\title{
A Geração de Emprego e Unidades Produtivas da Economia Criativa na Região do COREDE Sinos - RS Brasil de 2006 a 2009
}

Judite Sanson Bem ${ }^{1}$

Nelci Richter Giacomini ${ }^{2}$

Resumo: Atividades que se desenvolvem em uma região, utilizam os recursos a serem produzidos e geram resultados que afetam a economia e desencadeiam um efeito multiplicador sobre o emprego e renda. As atividades que envolvem a economia da cultura tem esse efeito sobre a economia, ou seja, os investimentos geram benefícios sobre outras atividades produtivas. O COREDE Vale do Rio dos Sinos - CONSINOS - é uma região politicamente instituída no início da década de 1990, pelo Governo do Estado do RS e tem como objetivo formular e implementar estratégias regionais, consolidando-os em planos regionais de desenvolvimento estratégico. É constituída por 14 municípios, com a produção industrial fortemente focada em cinco cidades: Campo Bom Canoas, Novo Hamburgo, São Leopoldo e Sapucaia. Economicamente, apresenta uma forte dependência do setor coureirocalçadista e de seus componentes, que resultaram em um problema dinâmico para a região, pois sofre grandes oscilações devido as questões cambiais e de exportação além da entrada de produtos chineses, entre outros. O objetivo é definir o que se entende por indústrias criativas e verificar pelo número de postos de trabalho e unidades de produção, se a região pode desenvolver a médio prazo, outras atividades que podem substituir a dependência do setor do calçado e, portanto, fazer outras possibilidades na matriz de produção.

Palavras-chave: emprego, economia criativa, indústrias criativas, Consinos

JEL: J20

\footnotetext{
1 Coordenadora Curso Ciências Econômicas e prof. Mestrado em Memória Social e Bens Culturais do Centro Universitário La Salle (UNILASALLE). Doutora em História pela PUCRS. E-mail: jsanson@terra.com.br 2 Prof $^{\text {a }}$ Titular e Pesquisadora do IEPE/UFRGS-(Aposentada da UFRGS), Prof ${ }^{\text {a }}$ de Economia do Centro Universitário La Salle (UNILASALLE). Mestre em Economia pela UFRGS. E-mail: nelcig@uol.com.br
} 


\title{
Generation of Employment and Production Unitis of Creative Economy in the Region of the COREDE Sinos - RS BRAZIL 2006-2009.
}

\begin{abstract}
Activities that develop in a region, using the resources to produce and generate results that affect the economy and trigger a multiplier effect on employment and income. Activities involving the economy of culture has this effect on the economy, ie, investments generate benefits over other productive activities. The COREDE Vale do Rio dos Sinos - CONSINOS - is a region politically instituted in the early 1990s, the Government of RS and aims to formulate and implement regional strategies, consolidating them into regional strategic development plans. It consists of 14 municipalities, with industrial production is heavily focused in five cities: Campo Bom, Canoas, Novo Hamburgo, São Leopoldo and Sapucaia. Economically, shows a strong dependence on the leather-footwear industry and its components, resulting in a dynamic problem for the region, since it undergoes large fluctuations due to exchange rate issues and export beyond the entry of Chinese products, among others. The goal is to define what is meant by creative industries and to verify the number of jobs and production units, if the region can develop in the medium term, other activities that can replace the dependence of the footwear sector and therefore do other matrix production possibilities.
\end{abstract}

Key-words: employment, creative economy, creative industries, Consinos

JEL: J20

\section{Introdução}

A economia da cultura tem por objetivo o estudo das relações entre as atividades culturais de uma região e as produtivas, gerando reflexos sobre emprego, geração de salários, lucros, prestação de serviços e produção de bens. A criatividade, fator preponderante na criação de bens e serviços que são produzidos e colocados no mercado pode ser um fator de melhoria das diferentes regiões estagnadas em função do exercício de atividades que no curto ou longo prazo serão substituídas parcialmente ou mesmo definitivamente da pauta da região.

Os municípios do Corede Vale do Rio dos Sinos - Consinos tem suas atividades concentradas na produção de químicos, petroquímicos, mas, sobretudo de calçados e todo o seu complexo. Região formada, basicamente, por imigrantes 
BEM, J.; GIACOMINI, N. A geração de emprego e unidades produtivas....

de origem alemã tiveram na produção e exportação do calçado 3 décadas de aumento de emprego, renda e indicadores de desenvolvimento. A partir da década de 1990, com a entrada do calçado chinês e de outros países asiáticos viu sua base ruir e aumentar os índices de desemprego e violência.

Com base nos dados do MTE/RAIS - CAGED utilizou-se os dados sobre emprego e renda para verificar, inicialmente, a posição dos municípios de Canoas e Campo Bom e compará-los ao RS, com o intuito de observar pontos de convergência ou não quanto às atividades consideradas criativas, desenvolvidas entre 2006 e 2009.

\section{Cultura, Economia Criativa e Indústrias Criativas}

A cultura deve ser compreendida como todas as formas de expressão artística e todo o patrimônio material e simbólico da sociedade, em que forma a memória e a identidade de um povo. Faria (2000, p. 19) argumenta que:

Cultura é, fundamentalmente, desenvolvimento humano: construção de valores da paz e da solidariedade, modos de vida culturalmente saudáveis, imaginário rico e eivado de utopias possíveis e impossíveis, geração de emprego e renda que valorize raízes e escolhas, identidades abertas e novas tendências, poéticas de um mundo novo. Enfim, é também um espetáculo que celebra a comunidade humana e não apenas o sombrio mundo dos negócios.

A cultura e as artes movimentam parte da economia mundial. Segundo Reis (2003, p. 51):

As relações entre economia e cultura são revestidas de grandes polêmicas no mundo acadêmico. Para alguns, se a cultura for compreendida [...] como o que dá a um povo sua distinção (valores, hábitos, atitudes, criações), a economia seria parte da própria cultura. O que nos interessa aqui, porém, é a forma como o setor cultural impulsiona a economia de um determinado local ou sociedade. Toda e qualquer atividade que se desenrola dentro de uma região, envolvendo recursos para ser produzida e gerando um resultado, afeta a economia. A proposta da economia da cultura é justamente avaliar esse efeito multiplicador das atividades culturais, ou seja, o impacto que esse investimento gera, comparado ao que custou 
BEM, J.; GIACOMINI, N. A geração de emprego e unidades produtivas....

A relação entre economia e cultura constitui-se em um instrumento analítico, para resolver questões ligadas aos efeitos econômicos da atividade cultural, como aquelas relacionadas à geração de emprego e renda, além das renúncias fiscais que envolvem o setor. Os efeitos multiplicadores das atividades culturais podem ser assim definidos:

Resumindo, a economia da cultura ganha relevância, na medida em que pode servir como propulsor da viabilização da economia da criação e da indústria da cultura, fazendo com que possa tornar eficaz a lógica produtiva de geração de renda e emprego.

Mais recentemente, década de 1990 em diante, a cultura passou a ser considerada com maior ênfase como uma ferramenta para o desenvolvimento sócio-econômico de um país uma vez que eleva a economia de uma região. $\mathrm{O}$ entendimento dessa questão vem se firmando como um desafio, pois engloba os conceitos de: indústria criativa e de economia criativa.

\subsection{A indústria criativa: definições e interpretações}

A Criatividade econômica é um processo dinâmico conducente à inovação em tecnologia, práticas comerciais, marketing, etc., e está ligada à obtenção de vantagens competitivas na economia.

A criatividade é um elemento-chave na definição do âmbito das indústrias criativas e da economia criativa. Criatividade pode ser definida como o processo pelo qual as idéias são geradas, ligados e transformados em coisas que são avaliadas (UNCTAD, 2009).

Do ponto de vista econômico a relação entre a criatividade e o desenvolvimento sócio econômico não é aparente, particularmente o grau de criatividade que contribui para o crescimento econômico.

\subsubsection{Bens e Serviços Culturais versus Bens e Serviços Criativos}

O âmbito da economia criativa é determinado pela medida das indústrias criativas, embora haja divergência na literatura, especialmente em relação ao conceito paralelo de "indústrias culturais". Duas situações ocorrem: às vezes é feita uma distinção entre a criatividade e as indústrias culturais, outras vezes os dois termos são utilizados alternadamente.

Uma alternativa para a definição de "bens e serviços culturais" deriva da análise do tipo de valor que eles geram. Isto é, estes bens e serviços têm valor cultural além de valor comercial e este valor cultural não pode ser plenamente 
mensurável em termos monetários. Em outras palavras, as atividades culturais de diversos tipos e os bens e serviços que produzem são valorizados - tanto por aqueles que os fazem como por aqueles que os consomem - por razões sociais e culturais podem complementar ou transcender uma avaliação puramente econômica. Se tal valor cultural pode ser identificado pela sociedade, ele pode servir como uma característica que os distingue em comparação com diferentes tipos de "commodities".

Os bens e serviços culturais podem ser vistos como um subconjunto de uma categoria mais ampla de produtos que podem ser chamados de "bens e serviços criativos". Trata-se de produtos que requerem algum nível de criatividade razoavelmente elevado. Assim, a categoria "mercadorias criativas" se estende para além dos bens culturais, tal como definido anteriormente, por incluir produtos como moda e software.

\subsubsection{Indústrias Culturais $x$ Indústrias Criativas}

O termo "indústria cultural" surgiu no período do pós-guerra por membros da escola de Frankfurt liderada por Theodor Adorno e Max Horkheimer.

Na UNESCO, por exemplo, as indústrias culturais são vistas como as indústrias que "combinam a criação, produção e comercialização de conteúdos que são intangíveis e culturais na natureza. Estes conteúdos são, normalmente, protegidos por direitos autorais e podem assumir a forma de bens ou serviços". Um aspecto importante da indústria cultural, segundo a UNESCO, é que eles são "central na promoção e manutenção da diversidade cultural e em garantir o acesso democrático à cultura" (UNCTAD, 2009).

A designação de "indústrias criativas", que tem se desenvolvido, desde então, amplia o âmbito das indústrias culturais para além das artes e marca uma mudança na abordagem para atividades potencialmente comerciais, pois estas, até recentemente, eram consideradas puramente ou predominantemente em termos não econômicos.

Modelos diferentes, quanto a classificação do que se entende por indústrias "núcleo" e "periféricas" dentro da economia criativa, foram apresentados nos últimos anos como um meio de proporcionar uma compreensão das características estruturais das indústrias criativas. 
BEM, J.; GIACOMINI, N. A geração de emprego e unidades produtivas....

\subsubsection{A classificação de indústrias criativas - UNCTAD}

O approach da UNCTAD sobre indústrias criativas amplia o conceito de "criatividade" de atividades artísticas tendo um forte componente de "[...] qualquer atividade econômica produzindo produtos simbólicos com uma grande dependência em matéria de propriedade intelectual e para um mercado tão amplo quanto possível” (UNCTAD, 2009, P. 8).

A UNCTAD faz uma distinção entre "as atividades a montante" (tradicionais atividades culturais, como artes cênicas e artes visuais) e "as atividades a jusante" (muito mais próximo do mercado, tais como a publicidade, publicação ou mídia) e argumenta que o segundo grupo deriva o seu valor comercial, do seu baixo custo e sua fácil transferência para outros domínios econômicos. Nesta perspectiva, as indústrias culturais formam um subconjunto das indústrias criativas.

Para entender a definição de indústrias criativas, sob a ótica da UNCTAD (2009), são considerados os seguintes aspectos destas atividades:

- envolvem os ciclos de criação, produção e distribuição de bens e serviços que usam criatividade e capital intelectual como insumos primários;

- constituem um conjunto de atividades com base no conhecimento, focado nas artes, mas não se limitando a, potencialmente geradoras de receitas provenientes de comércio e direitos de propriedade intelectual;

- compreendem produtos tangíveis e intelectuais intangíveis ou serviços artísticos com conteúdo criativo, valor econômico e com objetivos de mercado; - são o cruzamento entre o artesão, serviços e setores industriais, e constituem uma nova dinâmica no setor do comércio mundial.

A classificação de indústrias criativas da UNCTAD é dividida em quatro grandes grupos, quais sejam: patrimônio, artes, mídia e criações funcionais. Estes grupos são, por sua vez, divididos em nove subgrupos.

- O patrimônio reúne os aspectos culturais da história, antropologia, étnica, estética e pontos de vista sociais, é a origem de uma série de bens e serviços patrimoniais, bem como atividades culturais. Este grupo é, portanto, dividido em dois subgrupos:

- Tradicionais expressões culturais: artes e artesanato, festas e celebrações, e - Sítios Culturais: sítios arqueológicos, museus, bibliotecas, exposições, etc.

- Artes. Este grupo inclui as indústrias criativas baseadas puramente em arte e cultura. Este grupo é dividido em dois grandes subgrupos:

- Artes Visuais: pintura, escultura, fotografia e antiguidades; e

- Artes Cênicas: música ao vivo, teatro, dança, ópera, circo, fantoches, etc. 
- Mídia. Este grupo abrange dois subgrupos dos meios de comunicação que produzem conteúdo criativo com a finalidade de comunicação com grandes platéias ("nova mídia" é classificada separadamente). Subdivide-se em: - Publicação e mídia impressa: livros, imprensa e outras publicações, e - Audiovisuais: cinema, televisão, rádio e outros derivados da radiodifusão.

- Criações Funcionais. Este grupo inclui mais demanda dirigida e serviços orientados para indústrias, criando bens e serviços com fins funcionais. É dividida nos seguintes subgrupos:

- Design: Interiores, gráfica, moda, jóias, brinquedos;

- Novas mídias: software, jogos de vídeo, conteúdos criativos e digitalizados, - Serviços Criativos: arquitetura, publicidade, culturais e recreativas, pesquisa e desenvolvimento (I \& D), digital e outros serviços criativos relacionados. O desporto não está incluído na classificação de "indústrias criativas" UNCTAD.

Para IECB, o que caracteriza uma empresa criativa é a sua capacidade de se organizar de maneira a inovar, ou seja, o modo como desenha os processos, o modelo de negócios, como desenvolve os talentos.

Em decorrência de problemas estatísticos, o presente trabalho utilizou a classificação do IBGE - CNAE de atividades culturais para a análise em questão. Os autores estão cientes de que há problemas com a referida classificação, sobretudo em abrangência, mas os dados obtidos são confiáveis (Quadro 1).

\section{O CONSINOS e sua caracterização econômica}

O Estado do Rio Grande do Sul é dividido em 28 unidades de planejamento, os chamados Conselhos Regionais de Desenvolvimento (COREDE's), que foram divididos conforme suas características culturais e territoriais. Os COREDES/RS têm como Marco Legal a Lei 10.283 de 17 de Outubro de 1994. O Corede Vale do Rio dos Sinos - Consinos tinha uma população total em 2008 de 1.287.805 habitantes, e uma área de $1.398,5 \mathrm{~km}^{2}$. Fazem parte desta região, os municípios de: Araricá, Campo Bom, Canoas, Dois Irmãos, Estância Velha, Esteio, Ivoti, Nova Hartz, Nova Santa Rita, Novo Hamburgo, Portão, São Leopoldo, Sapiranga, Sapucaia do Sul. Sua disposição em relação ao RS está abaixo exposta ( Figura 1).

Quanto a participação percentual dos 14 municípios, no PIB nominal ( Tabela 1) do Consinos, destacam-se Canoas, Novo Hamburgo e São Leopoldo, representando 68,43\%, em 2006. Os municípios de Sapiranga, Campo Bom 
BEM, J.; GIACOMINI, N. A geração de emprego e unidades produtivas....

e Nova Hartz apresentaram uma queda expressiva em sua contribuição no PIB, pois a região considerada apresenta uma forte concentração na produção de calçados e seus componentes, não tendo diversificado sua pauta produtiva ao contrário de outros COREDEs do Estado, como o Serra. Além disso, a valorização do R \$ frente ao US \$ fez com houvesse uma redução das exportações e uma entrada de produtos chineses no mercado nacional, dado o menor preço destes concorrentes.

\begin{tabular}{|c|c|c|}
\hline \multicolumn{3}{|r|}{ Fabricacão de produtos de madeira cortica e material trancado exceto móveis } \\
\hline \multicolumn{2}{|c|}{17117.4} & Fabricação de produtos diversos de papel, cartolina, papelcartão e papelão ondulado \\
\hline \multirow[t]{3}{*}{18} & 18.1 & Atividade de impressão \\
\hline & 18.2 & Serviço de préimpressão e acabamentos gráficos \\
\hline & $1 \overline{8} .3$ & Reprodução de materiais gravados em qualquer suporte \\
\hline \multirow[t]{3}{*}{26} & 26.2 & Fabricação de equipamentos de informática e periféricos \\
\hline & 26.3 & Fabricação de equipamentos de comunicação \\
\hline & $\overline{2} \overline{6} . \overline{4}$ & Fabricação de aparelhos de recepção, reprodução, gravação e amplificação de áudio e vídeo \\
\hline \multirow[t]{4}{*}{32} & 32.1 & Fabricação de artigos de joalheria, bijuteria e semelhantes \\
\hline & 32.2 & Fabricação de ins trumentos musicais \\
\hline & $3 \overline{2} .3$ & Fabricação de artefatos para pesca e esporte \\
\hline & 32.4 & Fabricação de brinquedos e jogos recreativos \\
\hline 33 & 33.1 & Manutenção e reparação de máquinas e equipamentos \\
\hline \multirow[t]{2}{*}{46} & 46.4 & Comércio atacadista de produtos de consumo nãoalimentar \\
\hline & $4 \overline{6} . \overline{5}$ & Comércio atacadista de equipamentos e produtos de tecnologias de informação e \\
\hline \multirow[t]{2}{*}{47} & 47.6 & Comércio varejis ta de artigos culturais, recreativos e esportivos \\
\hline & 47.8 & Comércio varejista de produtos novos não especificados anteriormente e de produtos \\
\hline \multirow[t]{2}{*}{58} & 58.1 & Edição de livros, jornais, revis tas e outras atividades de edição \\
\hline & 58.2 & Edição integrada à impressão de livros, jornais, revistas e outras publicaç \\
\hline 59 & 59.1 & 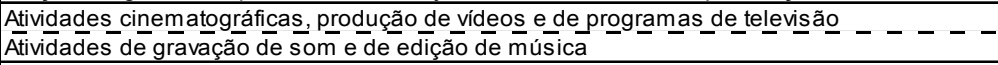 \\
\hline \multirow[t]{2}{*}{60} & 60.1 & Atividades de rádio \\
\hline & 60.2 & Atividades de televisão \\
\hline \multirow[t]{3}{*}{61} & $\begin{array}{l}61.1 \\
61.2 \\
61.3 \\
6\end{array}$ & 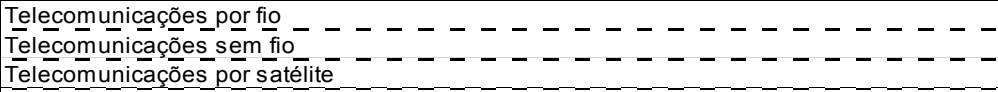 \\
\hline & 61.4 & Operadoras de televisão por as sinatura \\
\hline & 61.9 & Outras atividades de telecomunicações \\
\hline 62 & 62.0 & Atividades dos serviços de tecnologia da informação \\
\hline \multirow[t]{2}{*}{63} & 63.1 & Tratamento de dados, hospedagem na internet e outras atividades relacionadas \\
\hline & 63.9 & Outras atividades de prestação de serviços de informação \\
\hline 72 & 72.1 & 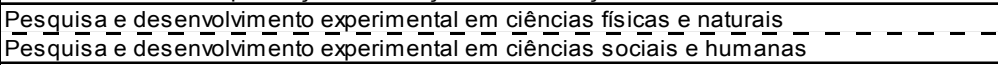 \\
\hline 73 & 73.1 & Publicidade \\
\hline 74 & 74.2 & Atividades fotográficas e similares \\
\hline 77 & 77.2 & Aluguel de objetos pessoais e domésticos \\
\hline 79 & 79.9 & Serviços de reservas e outros serviços de turismo não especificados anteriormente \\
\hline \multirow[t]{2}{*}{85} & 85.4 & Educação profiss ional de nível técnico e tecnológico \\
\hline & 85.9 & Outras atividades de ensino \\
\hline 90 & 90.0 & Atividades artísticas, criativas e de espetáculos \\
\hline 91 & 91.0 & Atividades ligadas ao patrimônio cultural e ambiental \\
\hline 93 & 93.2 & Atividades de recreação e laze \\
\hline
\end{tabular}

Fonte: LINS, 2011. 
BEM, J.; GIACOMINI, N. A geração de emprego e unidades produtivas....

Quanto a participação percentual dos 14 municípios, no PIB nominal ( Tabela 1) do Consinos, destacam-se Canoas, Novo Hamburgo e São Leopoldo, representando 68,43\%, em 2006. Os municípios de Sapiranga, Campo Bom e Nova Hartz apresentaram uma queda expressiva em sua contribuição no PIB, pois a região considerada apresenta uma forte concentração na produção de calçados e seus componentes, não tendo diversificado sua pauta produtiva ao contrário de outros COREDEs do Estado, como o Serra. Além disso, a valorização do $\mathrm{R}$ \$ frente ao $\mathrm{U}$ \$ fez com houvesse uma redução das exportações e uma entrada de produtos chineses no mercado nacional, dado o menor preço destes concorrentes.

\section{FIGURA 1: MUNICÍPIOS DO COREDE SINOS - CONSINOS}

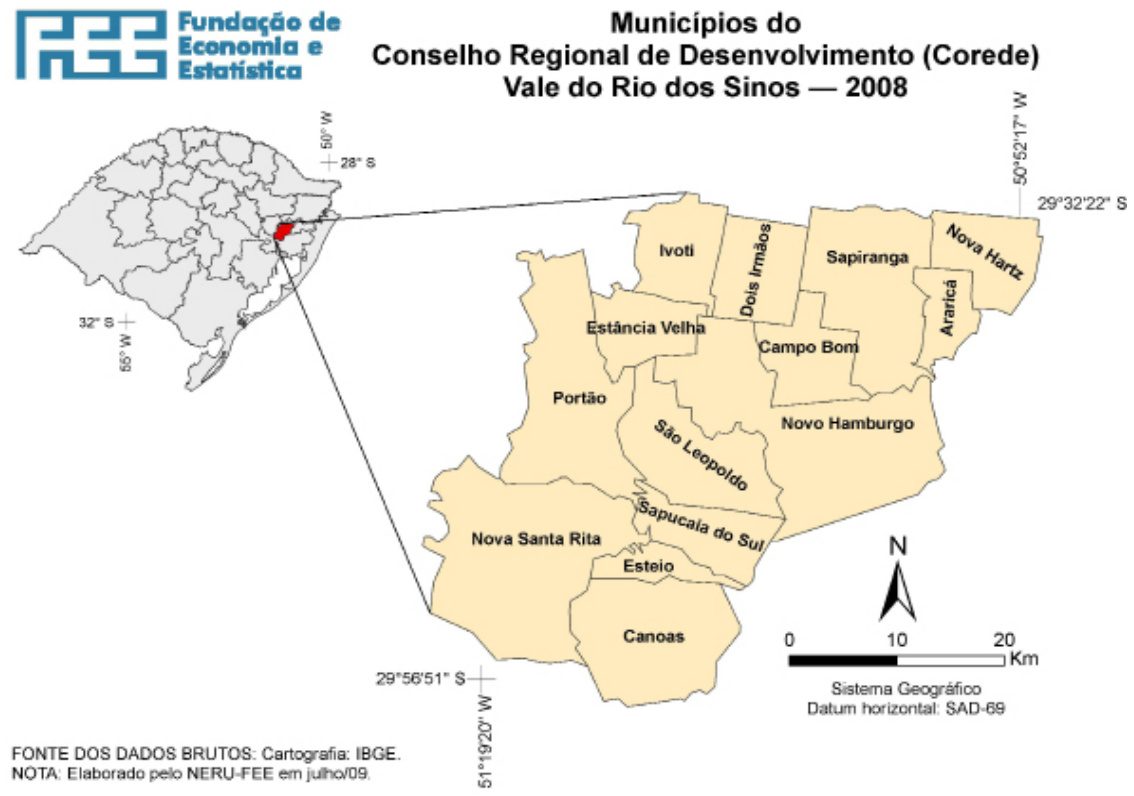

Fonte: FEE, 2010

Em relação à contribuição do setor secundário no VAB da Região/RS (Tabela 2) verifica-se que o mesmo setor reduziu sua parcela de participação, passando de $26 \%$ para 18\% ( uma alteração de 30\% em 12 anos). 
BEM, J.; GIACOMINI, N. A geração de emprego e unidades produtivas....

TABELA 1 PIB NOMINAL DE 2008 E PARTICIPAÇÃO DOS MUNICÍPIOS DO CONSINOS NO PIB/RS

\begin{tabular}{|c|c|c|c|c|c|c|}
\hline \multirow{2}{*}{ Municípios } & \multirow{2}{*}{$\begin{array}{l}\text { PIB } 2008 \text { (R\$ mil) } \\
\text { (valor nominal) }\end{array}$} & \multicolumn{5}{|c|}{ Participação percentual no COREDE } \\
\hline & & 1997 & 2000 & 2003 & 2006 & 2008 \\
\hline Araricá & 48.695 & 0,25 & 0,16 & 0,14 & 0,17 & 0,17 \\
\hline Campo Bom & 1.172 .837 & 6,36 & 6,49 & 5,08 & 4,73 & 4,12 \\
\hline Canoas & 12.580 .262 & 35,19 & 36,66 & 39,29 & 41,36 & 44,16 \\
\hline Dois Irmãos & 510.235 & 2,61 & 2,42 & 2,22 & 1,96 & 1,79 \\
\hline Estância Velha & 533.744 & 3,37 & 2,54 & 2,55 & 2,12 & 1,87 \\
\hline Esteio & 2.056 .261 & 6,74 & 6,95 & 7,27 & 7,26 & 7,22 \\
\hline Ivoti & 354.395 & 2,17 & 2,18 & 1,38 & 1,27 & 1,24 \\
\hline Nova Hartz & 289.297 & 1,95 & 1,33 & 1,00 & 0,99 & 1,02 \\
\hline Nova Santa Rita & 304.375 & 0,98 & 1,15 & 0,93 & 0,94 & 1,07 \\
\hline Novo Hamburgo & 4.418 .162 & 17,62 & 15,85 & 16,92 & 16,78 & 15,51 \\
\hline Portão & 584.919 & 2,06 & 2,91 & 2,76 & 2,18 & 2,05 \\
\hline São Leopoldo & 2.934 .147 & 9,06 & 9,19 & 10,18 & 10,29 & 10,30 \\
\hline Sapiranga & 992.934 & 5,29 & 4,31 & 3,86 & 3,62 & 3,49 \\
\hline Sapucaia do Sul & 1.705 .758 & 6,35 & 7,86 & 6,42 & 6,32 & 5,99 \\
\hline $\begin{array}{l}\text { COREDE Vale } \\
\text { dos Sinos }\end{array}$ & 28.486 .021 & 100,00 & 100,00 & 100,00 & 100,00 & 100,00 \\
\hline
\end{tabular}

Fonte: FEE, 2011 
BEM, J.; GIACOMINI, N. A geração de emprego e unidades produtivas....

TABELA 1 PIB NOMINAL DE 2008 E PARTICIPAÇÃO DOS MUNICÍPIOS DO CONSINOS NO PIB/RS (CONTINUAÇÃO)

\begin{tabular}{l|r|r|r|r|r|r}
\hline \multirow{2}{*}{ Municípios } & PIB 2008 (R mil) & \multicolumn{5}{|c}{ Participação percentual no RS } \\
\cline { 3 - 7 } (valor nominal) & 1997 & 2000 & 2003 & 2006 & 2008 \\
\hline Araricá & 48.695 & 0,04 & 0,03 & 0,02 & 0,02 & 0,02 \\
Campo Bom & 1.172 .837 & 1,08 & 1,11 & 0,76 & 0,70 & 0,59 \\
Canoas & 12.580 .262 & 5,97 & 6,28 & 5,90 & 6,12 & 6,31 \\
Dois Irmãos & 510.235 & 0,44 & 0,42 & 0,33 & 0,29 & 0,26 \\
Estância Velha & 533.744 & 0,57 & 0,43 & 0,38 & 0,31 & 0,27 \\
Esteio & 2.056 .261 & 1,14 & 1,19 & 1,09 & 1,08 & 1,03 \\
Ivoti & 354.395 & 0,37 & 0,37 & 0,21 & 0,19 & 0,18 \\
Nova Hartz & 289.297 & 0,33 & 0,23 & 0,15 & 0,15 & 0,15 \\
Nova Santa Rita & 304.375 & 0,17 & 0,20 & 0,14 & 0,14 & 0,15 \\
Novo Hamburgo & 4.418 .162 & 2,99 & 2,71 & 2,54 & 2,48 & 2,21 \\
Portão & 584.919 & 0,35 & 0,50 & 0,41 & 0,32 & 0,29 \\
São Leopoldo & 2.934 .147 & 1,54 & 1,57 & 1,53 & 1,52 & 1,47 \\
Sapiranga & 992.934 & 0,90 & 0,74 & 0,58 & 0,54 & 0,50 \\
Sapucaia do Sul & 1.705 .758 & 1,08 & 1,35 & 0,96 & 0,94 & 0,86 \\
\hline COREDE Vale & 28.486 .021 & 16,95 & 17,13 & 15,01 & 14,80 & 14,28 \\
dos Sinos & & & & & & \\
\hline Fonte: FEE, & & & & &
\end{tabular}

Fonte: FEE, 2011 
BEM, J.; GIACOMINI, N. A geração de emprego e unidades produtivas....

TABELA 2. PARTICIPAÇÃO DOS MUNICÍPIOS DO CONSINOS NO VAB INDUSTRIAL DO RS

\begin{tabular}{l|r|r|r|r|r|r}
\hline \multicolumn{1}{c}{ Município } & 1997 & 1998 & 1999 & 2000 & 2001 & 2002 \\
\hline Araricá & 0,06 & 0,04 & 0,04 & 0,04 & 0,02 & 0,03 \\
Campo Bom & 1,92 & 1,72 & 1,76 & 1,7 & 1,65 & 1,54 \\
Canoas & 9,36 & 9,03 & 8,01 & 9,43 & 9,8 & 7,44 \\
Dois Irmãos & 0,83 & 0,73 & 0,75 & 0,77 & 0,82 & 0,77 \\
Estância Velha & 0,98 & 0,86 & 0,74 & 0,7 & 0,74 & 0,74 \\
Esteio & 1,46 & 1,3 & 1,4 & 1,13 & 1,09 & 1,16 \\
Ivoti & 0,67 & 0,71 & 0,55 & 0,65 & 0,42 & 0,34 \\
Nova Hartz & 0,65 & 0,53 & 0,4 & 0,41 & 0,4 & 0,38 \\
Nova Santa Rita & 0,24 & 0,25 & 0,25 & 0,28 & 0,24 & 0,24 \\
Novo Hamburgo & 4,09 & 3,71 & 3,35 & 3,44 & 3,26 & 3,15 \\
Portão & 0,59 & 0,61 & 0,67 & 0,9 & 1,14 & 1,16 \\
São Leopoldo & 1,91 & 1,93 & 1,74 & 1,66 & 1,57 & 1,58 \\
Sapiranga & 1,51 & 1,49 & 1,44 & 1,2 & 1,17 & 1,19 \\
Sapucaia do Sul & 1,64 & 1,88 & 1,89 & 1,89 & 1,71 & 1,72 \\
\hline Vale do Rio dos Sinos & 25,92 & 24,79 & 22,99 & 24,2 & 24,03 & 21,44 \\
\hline RS & 100 & 100 & 100 & 100 & 100 & 100 \\
\hline
\end{tabular}

Fonte dos Dados Brutos: FEE, 2011 
BEM, J.; GIACOMINI, N. A geração de emprego e unidades produtivas...

TABELA 2. PARTICIPAÇÃO DOS MUNICÍPIOS DO CONSINOS NO VAB INDUSTRIAL DO RS (CONTINUAÇÃO)

\begin{tabular}{lrrrr|r|r|r}
\hline \multicolumn{1}{c|}{ Município } & 2003 & 2004 & 2005 & 2006 & 2007 & 2008 \\
\hline Araricá & 0,03 & 0,03 & 0,03 & 0,03 & 0,03 & 0,03 \\
Campo Bom & 1,36 & 1,35 & 1,24 & 1,16 & 0,99 & 0,86 \\
Canoas & 7,92 & 7,6 & 8,3 & 8,05 & 8,37 & 8,35 \\
Dois Irmãos & 0,65 & 0,61 & 0,5 & 0,44 & 0,38 & 0,36 \\
Estância Velha & 0,72 & 0,57 & 0,51 & 0,46 & 0,39 & 0,35 \\
Esteio & 1,18 & 0,99 & 0,95 & 0,89 & 0,80 & 0,75 \\
Ivoti & 0,31 & 0,28 & 0,3 & 0,24 & 0,22 & 0,24 \\
Nova Hartz & 0,32 & 0,27 & 0,27 & 0,29 & 0,28 & 0,29 \\
Nova Santa Rita & 0,23 & 0,21 & 0,18 & 0,19 & 0,19 & 0,21 \\
Novo Hamburgo & 2,88 & 2,72 & 2,63 & 2,51 & 2,31 & 2,12 \\
Portão & 0,96 & 0,94 & 0,7 & 0,62 & 0,65 & 0,58 \\
São Leopoldo & 1,65 & 1,63 & 1,67 & 1,68 & 1,73 & 1,64 \\
Sapiranga & 1,01 & 0,92 & 0,8 & 0,76 & 0,75 & 0,74 \\
Sapucaia do Sul & 1,73 & 1,78 & 1,73 & 1,59 & 1,50 & 1,5 \\
\hline Vale do Rio dos Sinos & 20,94 & 19,91 & 19,81 & 18,92 & 18,59 & 18,02 \\
\hline RS & 100 & 100 & 100 & 100 & 100 & 100 \\
\hline
\end{tabular}

Fonte dos Dados Brutos: FEE, 2011 
BEM, J.; GIACOMINI, N. A geração de emprego e unidades produtivas....

O PIB per capita do Corede Vale do Rio dos Sinos (Tabela 3) é superior ao do Rio Grande do Sul em todos os anos da série. Em alguns anos, como 2000 e 2001 esta diferença chegou a alcançar ao redor de 26\% (em 1997 esta diferença foi de 31,5\%). No entanto, gradativamente, esta diferença diminui e, em 2006, equivale a $18,4 \%$. No período, nominalmente, o PIBpc do RS cresceu 147,9\%, e do Consinos $134,75 \%$.

TABELA 3. PIB PER CAPITA DO RS E DO CONSINOS

\begin{tabular}{cccc}
\hline Ano & $\begin{array}{c}\text { Corede Vale do Rio } \\
\text { do Sinos - Consinos }\end{array}$ & $\begin{array}{c}\text { Estado do Rio } \\
\text { Grande do Sul }\end{array}$ \\
\hline 2000 & 10.871 & 7.978 \\
2001 & 12.098 & 8.900 \\
2002 & 13.029 & 10.057 \\
2003 & 14.778 & 11.742 \\
2004 & 16.826 & 12.850 \\
2005 & 16.981 & 13.298 \\
2006 & 17.512 & 14.305 \\
2007 & 19.901 & 16.689 \\
2008 & 23.469 & 18.378 \\
2009 & 25.520 & 19.778 \\
\hline
\end{tabular}

Fonte: FEE, 2011

Em relação às exportações dos municípios (Tabela 4) verifica-se que Canoas, Campo Bom e Novo Hamburgo apresentaram as maiores participações, em termos de valor, no Consinos.

Os principais produtos exportados pela região são: calçados de couro c/sola de couro, plásticos, borracha, partes de calçados; palmilhas; polainas; perneira; motores de pistão, de ignição por compressão óleos de petróleo ou de minerais betuminosos, ouros/peles, depilados, bovinos/eqüídeos preparados.

Quanto ao comportamento das exportações do Consinos, junto ao RS, este vem perdendo espaço desde 2003, tendo apenas Canoas e São Leopoldo aumentado-as no período considerado. Houve variações médias negativas no período, nos casos de Novo Hamburgo (calçados e seus componentes), Sapucaia, Ivoti e sobremaneira Nova Hartz (-17,9\%). Estes declínios estão associados à apreciação do dólar americano (U\$) frente ao real (R\$).

De acordo com a Tabela 4, Canoas é o primeiro município em volume de exportação do Corede Vale do Rio dos Sinos, tendo obtido uma taxa média de crescimento superior aos demais municípios do mesmo porte da região. 
BEM, J.; GIACOMINI, N. A geração de emprego e unidades produtivas....

Campo Bom devido a crise que se abateu sobre o setor calçadista apresentou uma parca participação no período considerado, embora não tenha apresentado uma variação negativa como Novo Hamburgo, cidade média e com indicadores díspares em comparação.

Entre os principais produtos exportados por Canoas estão: gasolinas, óleos combustíveis, tratores e partes para tratores e veículos, totalizando ao redor de $70 \%$ do total. O município de Campo Bom exportava, no período considerado, outros calcados de couro natural, outros calcados de couro natural cobrindo o tornozelo, outros calcados de couro natural e sola exterior de couro, outras partes de calcados, etc. de outros materiais, outros calcados de borracha/plástico cobrindo tornozelo. Estes produtos totalizam mais de $80 \%$ de suas exportações.

Quanto ao indicador de desenvolvimento econômico e social - IDESE do Consinos, em todos os sete anos este é superior ao do Rio Grande do Sul e em ambos os casos é crescente. Nos blocos saneamento, domicílios e educação, o valor do Consinos é inferior ao do RS, e nos outros dois, renda e saúde é superior ao Estado, conferindo-lhe o somatório superior do indicador geral.

\section{Unidades produtivas, geração de emprego e renda das atividades criativas. Uma Alternativa de Desenvolvimen- to para o Consinos}

Esta região considerada no presente estudo caracteriza-se, como exposto acima por ser industrializada e voltada, basicamente, para a produção coureiro calçadista. No entanto, após sucessivos anos de crise no setor, as diferentes tentativas de redirecionamento da matriz produtiva não necessariamente apresentaram os resultados imediatos desejados, já que as raízes e, sobretudo a existência de perfeita mobilidade dos capitais, não se aprestam como nos livros textos.

As sugestões e pertinências de atividades alternativas podem ser observadas nas figuras que seguem (2 a 4) e sua análise comparativa ao Estado do Rio Grande do Sul - RS (5 a 7). A primeira variável pelo trabalho analisada, e considerada importante como fonte de crescimento regional diz respeito ao número de estabelecimentos das diferentes atividades produtivas. A figura 2 apresenta o comportamento do número de estabelecimentos das atividades criativas, anteriormente apresentadas no Quadro 1, para a região estudada no período compreendido entre 2006 e 2009. 
BEM, J.; GIACOMINI, N. A geração de emprego e unidades produtivas....

TABELA 4. EXPORTAÇÕES E TAXA MÉDIA DE CRESCIMENTO DAS EXPORTAÇÕES DOS MUNICÍPIOS DO COREDE SINOS E DO RIO GRANDE DO SUL NO PERÍODO 2000 A 2010

\begin{tabular}{|c|c|c|c|c|c|c|c|c|}
\hline \multirow{2}{*}{ Municípios } & Exportações 2010 & \multicolumn{6}{|c|}{ Participação percentual dos municípios } & \multirow{2}{*}{$\begin{array}{c}\text { Taxa } \\
\text { média } \\
\text { cresci- } \\
\text { mento } \\
\text { expor- } \\
\text { tações } \\
2000- \\
2010\end{array}$} \\
\hline & US\$ (FOB) & 2000 & 2002 & 2004 & 2006 & 2008 & 2010 & \\
\hline Canoas & 956.335 .114 & 12,7 & 14,2 & 25,4 & 35,1 & 44,6 & 40,8 & 52,7 \\
\hline $\begin{array}{l}\text { São } \\
\text { Leopoldo }\end{array}$ & 342.846 .041 & 6,39 & 5,8 & 7,6 & 8,64 & 10,7 & 14,6 & $-3,2$ \\
\hline Campo Bom & 200.605 .324 & 18,4 & 17,8 & 14,1 & 12,1 & 8,42 & 8,56 & 17,4 \\
\hline $\begin{array}{l}\text { Novo } \\
\text { Hamburgo }\end{array}$ & 188.537 .996 & 14,9 & 16,4 & 14,9 & 12,3 & 8,27 & 8,04 & $-2,7$ \\
\hline Sapiranga & 164.022 .079 & 13,6 & 12,5 & 8,5 & 8,05 & 8,79 & 7,00 & 0,0 \\
\hline Portão & 130.012 .335 & 4,68 & 6,70 & 4,4 & 4,84 & 3,74 & 5,55 & $-0,9$ \\
\hline Dois Irmãos & 111.094 .256 & 9,69 & 9,75 & 8,3 & 5,88 & 5,15 & 4,74 & $-6,6$ \\
\hline $\begin{array}{l}\text { Estância } \\
\text { Velha }\end{array}$ & 109.910 .984 & 7,29 & 7,05 & 6,1 & 4,59 & 3,42 & 4,69 & 11,4 \\
\hline Esteio & 59.479 .934 & 4,33 & 4,08 & 3,9 & 2,81 & 3,05 & 2,54 & $-11,1$ \\
\hline $\begin{array}{l}\text { Sapucaia do } \\
\text { Sul }\end{array}$ & 37.556 .423 & 2,15 & 1,07 & 2,6 & 2,10 & 2,20 & 1,60 & $-1,7$ \\
\hline Ivoti & 24.169 .869 & 3,17 & 2,01 & 2,8 & 2,24 & 1,06 & 1,03 & 6,3 \\
\hline Nova Hartz & 11.758 .457 & 2,52 & 2,47 & 1,8 & 1,20 & 0,35 & 0,50 & 13,5 \\
\hline $\begin{array}{l}\text { Nova Santa } \\
\text { Rita }\end{array}$ & 6.779 .291 & 0,15 & 0,14 & 0,7 & 0,19 & 0,23 & 0,29 & $-2,2$ \\
\hline Araricá & 865.895 & 0,00 & 0,00 & 0,0 & 0,01 & 0,02 & 0,04 & 1,5 \\
\hline $\begin{array}{l}\text { Corede Sinos } \\
\text { (US\$ 1.000) }\end{array}$ & 2.343 .973 .998 & 100 & 100 & 100 & 100 & 100 & 100 & 2,8 \\
\hline $\begin{array}{l}\text { RS (Em US\$ } \\
1.000 .000)\end{array}$ & 14.672 & 5.78 & 6.38 & 9.9 & 11.2 & 17.1 & 14.7 & 9,7 \\
\hline $\begin{array}{l}\% \text { SINOS/ } \\
\text { RS }\end{array}$ & 15,98 & 26,1 & 23,5 & 20,6 & 22,62 & 18,6 & 15,9 & \\
\hline
\end{tabular}

Fonte: MDIC, 2011 


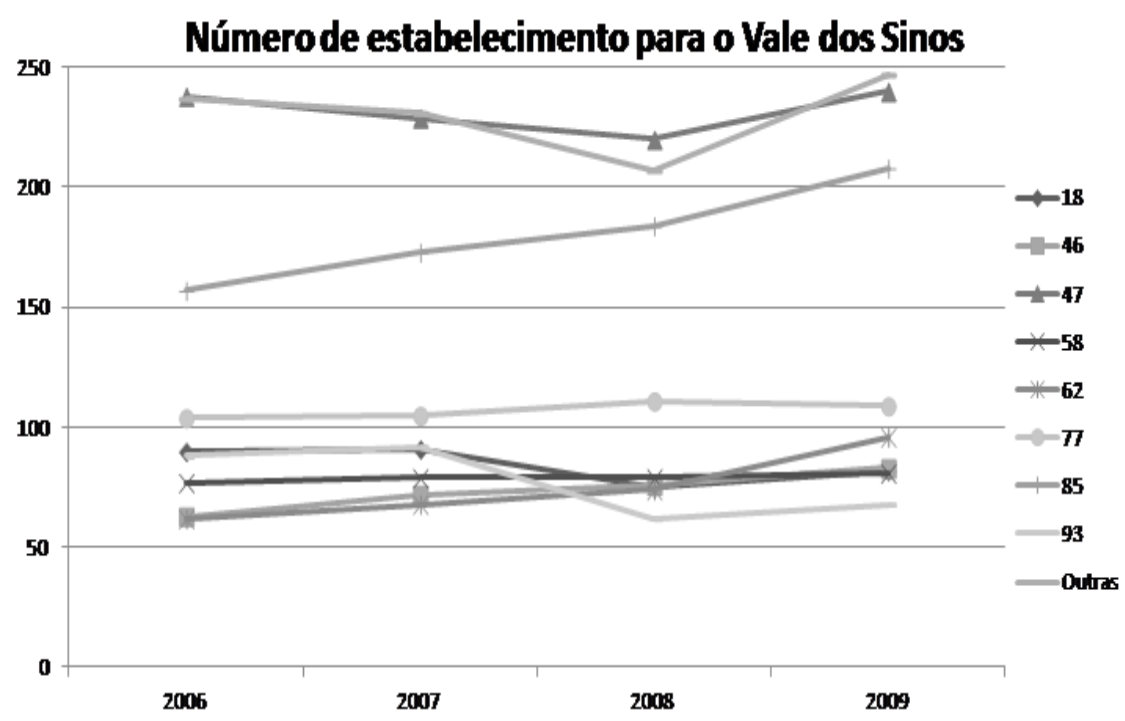

Fonte: Autores

FDB: MTE - RAIS/CAGED, 2011

Entre as atividades que se sobressaem quanto ao número de estabelecimentos, observa-se na figura 2 que estão: comércio varejista de artigos culturais, recreativos e esportivos, educação profissional de nível técnico e tecnológico, bem como outras atividades de ensino; aluguel de objetos pessoais; atividades dos serviços de tecnologia da informação. As demais atividades ainda não apresentam significativa participação no número de estabelecimentos criativos da região.

Pode-se, também, medir a importância de determinadas atividades produtivas por seus indicadores socioeconômicos. Entre eles podem ser citados aqueles relacionados ao mercado de trabalho.

O mercado de trabalho pode ser definido como um intercâmbio cotidiano da capacidade produtiva entre trabalhadores e empresas, que, juntamente com suas instituições, alocam recursos e renda entre si. Machado et al. (2010)

O mercado de trabalho se processa de forma que, o trabalho é a mercadoria e o preço do trabalho é representado pelo salário. O presente artigo utilizou-se dos conceitos do Ministério do Trabalho e Emprego, Instituto Brasileiro de Geografia e Estatística, entre outros. 
BEM, J.; GIACOMINI, N. A geração de emprego e unidades produtivas....

O número de empregos em determinado período de referência corresponde ao total de vínculos empregatícios efetivados. O número de empregos difere do número de pessoas empregadas, uma vez que o indivíduo pode estar acumulando, na data de referência, mais de um emprego. (IBGE, 2011)

Entende-se por vínculos empregatícios as relações de emprego, estabelecidas sempre que ocorre trabalho remunerado. São consideradas como vínculos as relações de trabalho dos celetistas, dos estatutários, dos trabalhadores regidos por contratos temporários, por prazo determinado, e dos empregados avulsos, quando contratados por sindicatos. (IBGE, 2011)

Assim, a figura 3 apresenta o número de vínculos, empregos, nas atividades criativas da região do Consinos, entre 2006 e 2009.

Nesta variável não há obrigatoriamente o mesmo perfil de interpretação do ocorrido como o número de estabelecimentos: aqui há crescimento significativo com os empregos nas atividades (educação profissional de nível tecnológico e técnico; outros serviços de tecnologia da informação) e um decréscimo no emprego de: edição de livros, jornais, revistas, e outros; atividades de impressão, préimpressão, acabamentos gráficos e reprodução de materiais.

A terceira variável econômica em destaque na análise das indústrias criativas é a renda. Para tal faz-se necessário algumas definições ( IBGE, 2011):

FIGURA 3 - NÚMERO DE EMPREGOS DAS ATIVIDADES DA INDÚSTRIA CRIATIVA NO COREDE VALE DO RIO DOS SINOS, RS - NO PERÍODO DE 2006 A 2009

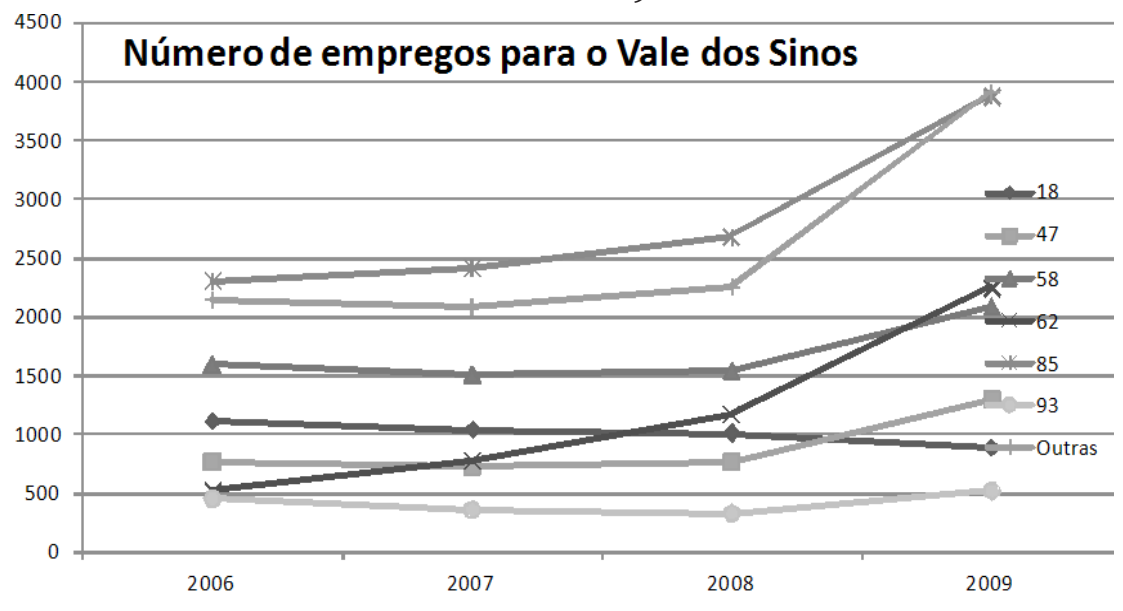

Fonte: Autores

FDB:MTE - RAIS/CAGED, 2011 
BEM, J.; GIACOMINI, N. A geração de emprego e unidades produtivas....

- Remuneração média mensal em salário mínimo- A remuneração média mensal em salários mínimos é definida como a média aritmética das remunerações individuais no mês de referência, convertidas em salários mínimos, no período vigente do ano-base. Integram essa remuneração os salários, ordenados, vencimentos, honorários, vantagens, adicionais, gratificações, etc. Está excluída a remuneração do $13^{\circ}$ salário;

- Massa salarial - É o resultado do produto entre a remuneração média dos empregados em dezembro e o número de empregos existentes no dia 31 do mesmo mês. Nesse indicador, as informações são fornecidas em salários mínimos vigentes na época ou em valor nominal (moeda corrente da época) a partir do ano base 1999. A figura 4 apresenta a remuneração das principais atividades criativas do Consinos entre os anos em estudo.

Percebe-se que as maiores remunerações do Corede Sinos provêm das atividades de educação profissional de nível técnico e tecnológico, outras atividades de ensino; da edição de livros, jornais e revistas entre outros; e das atividades de impressão. Estas atividades correspondem, em sua maioria, as mesmas atividades que mais empregam (figura 3).

\section{FIGURA 4 - RENDA DAS ATIVIDADES DA INDÚSTRIA CRIATIVA NO COREDE VALE DO RIO DOS SINOS, RS - NO PERÍODO DE 2006 A 2009}

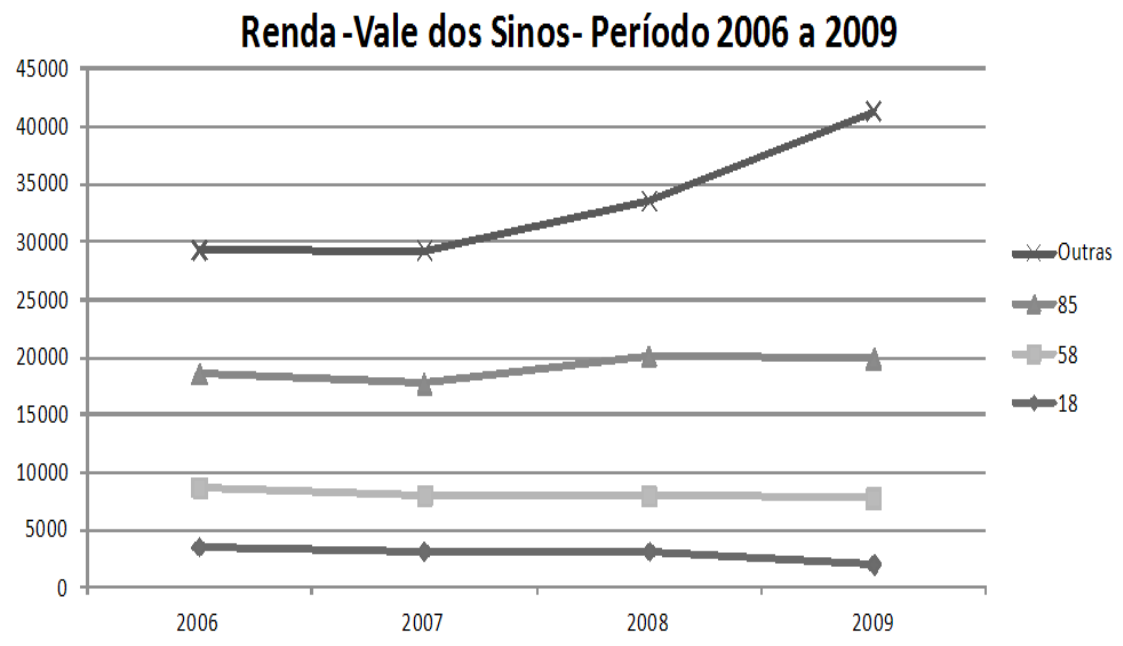

Fonte: Autores

FDB:MTE - RAIS/CAGED, 2011 
BEM, J.; GIACOMINI, N. A geração de emprego e unidades produtivas....

Percebe-se que as maiores remunerações do Corede Sinos provêm das atividades de educação profissional de nível técnico e tecnológico, outras atividades de ensino; da edição de livros, jornais e revistas entre outros; e das atividades de impressão. Estas atividades correspondem, em sua maioria, as mesmas atividades que mais empregam (figura 3).

O Estado do Rio Grande do Sul (figura 5) quanto ao número de estabelecimentos apresenta uma configuração, em parte, semelhante à região Corede Vale do Rio dos Sinos no que se refere às atividades criativas como: atividades de impressão e pré-impressão; comércio varejista de livros, jornais, revistas e papelaria, edições de livros, revistas e atividades de recreação e lazer.

FIGURA 5 - NÚMERO DE ESTABELECIMENTOS DAS ATIVIDADES DA INDÚSTRIA CRIATIVA NO ESTADO DO RIO GRANDE DO SUL - NO PERÍODO DE 2006 A 2009

Número de estabelecimentos do RS - período 2006 a 2009

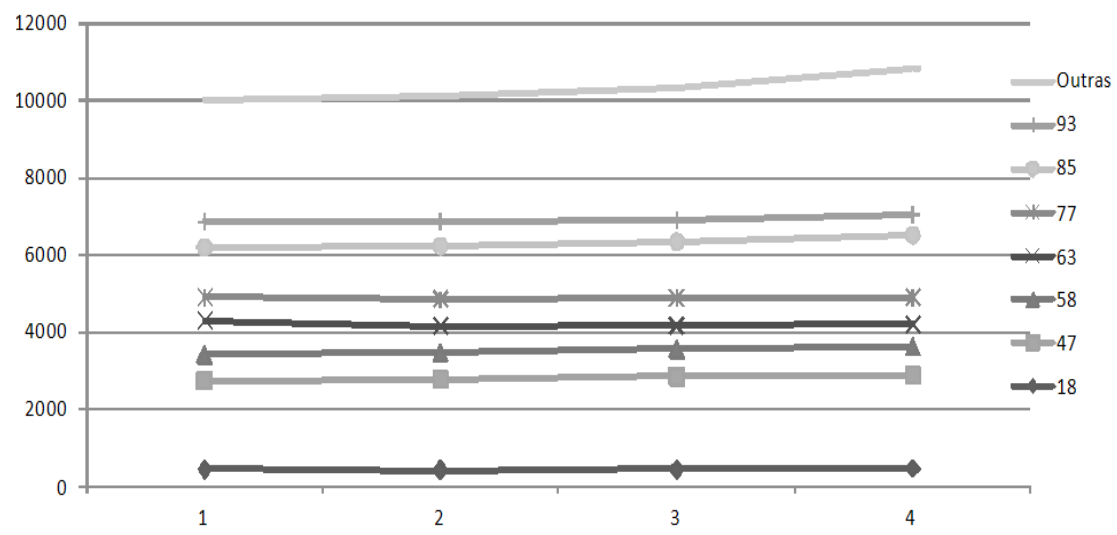

Fonte: Autores

FDB: MTE - RAIS/CAGED, 2011

Mas, em contrapartida, o Estado do RS apresenta outra gama de atividades que o torna díspar, em termos de emprego (figura 6), em relação ao Consinos como: atividades de lazer e recreação; educação profissional de nível técnico e tecnológico; pesquisa e desenvolvimento experimental em ciências físicas e naturais, sociais e humanas; tratamento de dados, hospedagem na internet e outras atividades relacionadas. Assim, há uma compreensão de que para o Consinos o emprego nas atividades criativas se concentra em algumas atividades enquanto no RS há outra disposição. 
BEM, J.; GIACOMINI, N. A geração de emprego e unidades produtivas....

FIGURA 6 - NÚMERO DE EMPREGOS NAS ATIVIDADES DA INDÚSTRIA CRIATIVA NO ESTADO DO RIO GRANDE DO SUL NO PERÍODO

DE 2006 A 2009

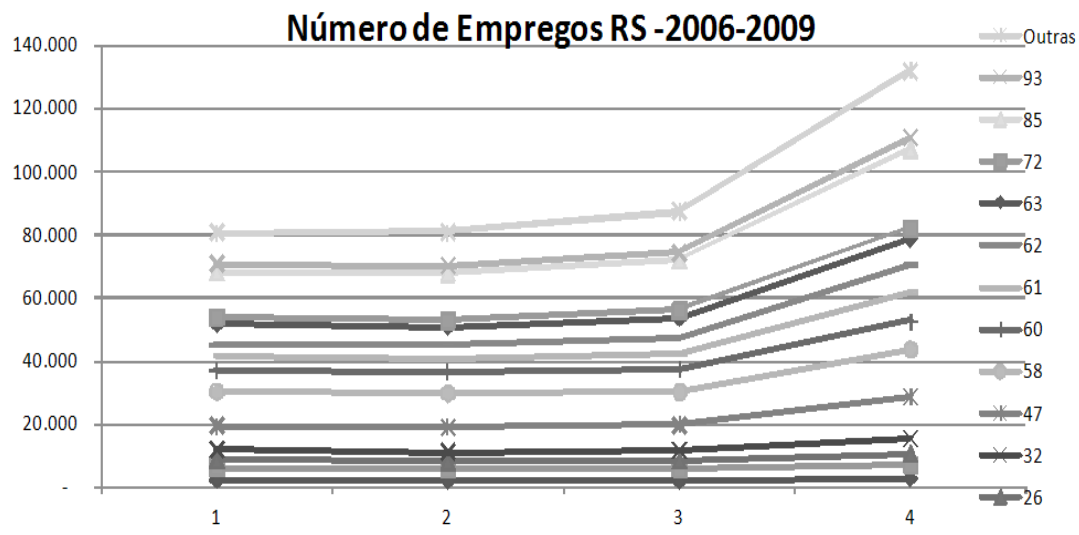

Fonte: Autores

FDB: MTE - RAIS/CAGED, 2011

Quanto a renda média paga nas atividades criativas (figura 7) a ordem passa a ser educação profissional, pesquisa e desenvolvimento experimental em ciências físicas e naturais; tratamento de dados, provedores de serviços de aplicação e serviços de hospedagem na internet, e seus desdobramentos. Atividades relacionadas a área de telecomunicações por fio, sem fio e por satélite, atividades ligadas a operação de televisão por assinatura/cabo, as atividades ligadas a licenciamento de programas de softwares e consultoria e TI. 
BEM, J.; GIACOMINI, N. A geração de emprego e unidades produtivas....

\section{FIGURA 7 - RENDA DAS ATIVIDADES DA INDÚSTRIA CRIATIVA NO ESTADO DO RIO GRANDE DO SUL - NO PERÍODO DE 2006 A 2009}

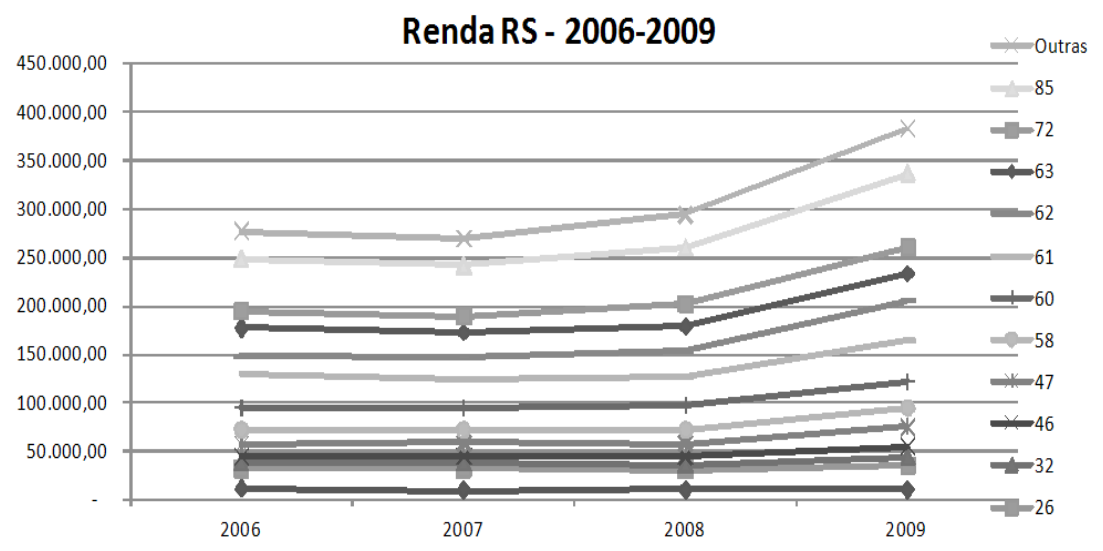

Fonte: Autores

FDB: MTE - RAIS/CAGED, 2011

\section{Considerações Finais}

Sendo a cultura compreendida como todas as formas de expressão artística e todo o patrimônio material e simbólico da sociedade, tal conjunto é essencial para a memória e a identidade do país.

A cultura não é apenas algo que dá prazer, que entretém o ser humano, mas também é o meio de construção de valores, identidades em que os indivíduos e a sociedade podem usufruir de uma existência intelectual, moral e afetiva, na medida em que as atividades culturais estimulam a imaginação, a auto-estima, a sensibilidade e as capacidades crítica e criativa.

Uma dimensão da cultura, pela qual toda a sociedade se beneficia, é a econômica. As atividades culturais como artesanato, festivais, gastronomia, shows, espetáculos, cinema, entre outras, promovem um impacto econômico positivo para a localidade onde são realizadas. Para executar as atividades culturais é necessário ações, como: ser uma atividade jurídica, contratar mão de obra, realizar dispêndios, como locação, restauração ou construção de imóveis, compra de equipamentos, contratação de serviços, entre outros.

A designação de "indústrias criativas", que este artigo trabalha tem se desenvolvido, desde a década de 1980, ampliando a que anteriormente se conhecia como indústrias culturais para além das artes e marcando uma mudança na abordagem para atividades potencialmente comerciais, pois estas, até recentemente, eram consideradas puramente ou predominantemente em termos não econômicos. A criatividade é a mola propulsora destas atividades criativas. Como seu principal fator de trabalho é a capacidade do seu humano 
BEM, J.; GIACOMINI, N. A geração de emprego e unidades produtivas....

em se reciclar, estudar aumentar seus conhecimentos, estas atividades podem mudar o desempenho de uma região. Neste sentido a regiões com dificuldades de crescimento podem pensar a criatividade e as atividades a ela associadas como uma forma de mudar suas oportunidades.

\section{Referências bibliográficas}

BARACHO, M. A. P.; REIS, A. (2001). Estado, Cultura e Mercado na era da globalização: Reflexões e Possibilidades. URL [on-line]: <http://www. duo.inf.br/culturaonline/arquivos/baracho_e_reis.pdf $>$. Acesso em 30 mar. 2008.

BRASIL. MINISTÉRIO DO DESENVOLVIMENTO INDÚSTRIA E COMÉRCIO - MDIC. Estatísticas de Comércio Exterior. URL [on-line]: <http:// aliceweb.desenvolvimento.gov.br>. Acesso em: 20 de fevereiro de 2011.

BRASIL. MINISTÉRIO DO TRABALHO E EMPREGO, Bases Estatísticas RAIS / CAGED. URL [on-line]: <http://sgt.caged.gov.br/index.asp>. Acesso em: o8 de março de 2011.

BRASIL. INSTITUTO BRASILEIRO DE GEOGRAFIA E ESTATÍSTICA - IBGE. Comitê se Estatísticas Sociais. Base de dados. URL [on-line]: < http:// www.ibge.gov.br/comite_estatisticas_sociais/metadados_rais.php $>$. Acesso em: 04/03/2011.

FARIA, H. (2000). O desenvolvimento cultural como desafio: desenvolvimento cultural e plano de governo. São Paulo: Polis.

FUNDAÇÃO DE ECONOMIA E ESTATÍSTICA - FEE. Corede Vare do Rio dos Sinos. URL [on-line]: <http://www.fee.tche.br/sitefee/pt/content/ resumo/pg_coredes_detalhe.php?corede $=$ Vale + do + Rio + dos + Sinos $>$. Acesso em: $10 . f e v .2010$.

FUNDAÇÃO DE ECONOMIA E ESTATÍSTICA - FEE. Feedados. URL [on-line]:<http://www.fee.rs.gov.br/feedados/consulta/bcksel_corede. asp? caption=Coredes $>$. Acesso em: 20.ago.2011.

INSTITUTO DA ECONOMIA CRIATIVA DO BRASIL. Sobre a Economia Criativa. URL [on-line]: <http://www.economiacriativa.com/ec/pt/ instituto/index.asp>. Acesso em: 03. fev. 2011. 
LINS, C. P. (2003). A objetividade das políticas públicas de cultura e a construção de indicadores Culturais. Rio de Janeiro: IBGE/Diretoria de Pesquisas. URL [on-line]: <http://www.ibge.gov.br/home/estatistica/ populacao/indic_culturais/2003/default.shtm>. Acesso em: 10. fev. 2011.

MACHADO, F. A. et al. Economia social - mercado de trabalho, pobreza e desigualdade e criminalidade. URL [on-line]: <http://www.cedeplar. ufmg.br/pesquisas/pbh/arquivos/mod9parte1.pdf $>$.

MINISTÉRIO DA CULTURA. MINC. Execução Orçamentária por segmento cultural e região - 1995 a 2007. URL [on-line]: <www.cultura.gov.br/ site/wp-content/uploads/2008/o6/execucao-orcamentaria_segmento_regiao-1995-a-20072.pdf>. Acesso em: 30 de maio de $200 \overline{8}$.

REIS, A. C. F. (2003). Marketing cultural e financiamento da cultura: teoria e prática em um estudo internacional comparado. São Paulo: Pioneira Thompson Learning.

REIS, A. C. F. (2007). Economia da cultura e desenvolvimento sustentável: o caleidoscópio da cultura. São Paulo: Manole.

UNITED NATIONS CONFERENCE ON TRADE AND DEVELOPMENT - UNCTAD. Creative Economy. Report 2008. Geneva; New York: UNCTAD; UNDP, 2008, p. 9-16. URL [on-line]: <http://www.unctad. org/Templates/WebFlyer.asp?intItemID=5109\&lang=1. Acesso em: 07.fev.2009.

VALIATI, L.; FLORISSI, S. (orgs.). (2007). Economia da cultura: bem-estar econômico e evolução cultural. Porto Alegre: Editora da UFRGS.

Recebido em: 10 de abril de 2012 Aceito em: 15 de maio de 2013 